\title{
EFEITO DE CITOCININAS NA SENESCÊNCIA E ABSCISÃO FOLIAR DURANTE O CULTIVO IN VITRO DE Annona glabra L. ${ }^{1}$
}

\author{
LENALDO MUNIZ DE OLIVEIRA ${ }^{2}$, RENATO PAIVA ${ }^{3}$, JOSÉ RANIERE FERREIRA DE SANTANA ${ }^{4}$, \\ RAÍRYS CRAVO NOGUEIRA ${ }^{5}$, FERNANDA PEREIRA SOARES ${ }^{6}$, LUCIANO COUTINHO SILVA $^{7}$
}

RESUMO - A micropropagação de anonáceas tem sido limitada pela abscisão foliar precoce nas brotações, o que dificulta a manutenção e o desenvolvimento das plantas in vitro. Esse fato se deve, principalmente, ao acúmulo de etileno nos tubos fechados e à relação etileno/citocinina nas folhas. Assim sendo, avaliaram-se o efeito de fontes de citocinina sobre o retardo da senescência foliar em brotações de Annona glabra L. e suas implicações sobre o seu desenvolvimento. Segmentos nodais foram cultivados em tubo de ensaio contendo $15 \mathrm{~mL}$ do meio WPM, suplementado com $30 \mathrm{~g} \mathrm{~L}^{-1}$ de sacarose, $500 \mathrm{mg} \mathrm{L}^{-1}$ de benomyl e $1 \mathrm{~g} \mathrm{~L}^{-1}$ de carvão ativado. A esse meio adicionaram-se 6-benzilaminopurina, thidiazuron, cinetina e zeatina, todos na concentração de $1 \mathrm{mg} \mathrm{L}^{-1}$. Decorridos 45 dias após a inoculação, plantas foram submetidas à senescência em ambiente escuro, por um período de 9 dias, coletando-se folhas a cada três dias para quantificação de clorofila "a", clorofila "b", carotenóides, proteínas e açúcares solúveis totais. No final das fases de multiplicação e enraizamento, quantificaram-se a matéria seca, a área foliar e o número de folhas que sofreram abscisão nas plantas que não foram submetidas à senescência. Adotou-se o delineamento em blocos casualizados, sendo que cada período de senescência constituiu um bloco, com quatro repetições por tratamento. Os resultados mostraram que cinetina e zeatina, seguidas de thidiazuron e 6-benzilaminopurina, preservam maior teor de clorofilas "a", "b" e de carotenóides durante todo o período de senescência induzida. 6-benzilaminopurina e cinetina promoveram maior retenção da área foliar durante as fases de multiplicação e enraizamento de Annona glabra L.

Termos para indexação: Clorofila, Annonaceae, Carotenóide.

\section{EFFECT OF CYTOKININS ON SENESCENCE AND FOLIAR ABSCISION DURING IN VITRO Annona glabra L. CULTIVATION}

\begin{abstract}
The micropropagation of Annonaceae has been limited by early foliar abscission in shoots, which makes the maintenance and development of plants in vitro environment difficult. This is mainly due to ethylene accumulation in closed tubes and the ethylene/cytokinin ratio in leaves. Based in these circumstances it was evaluated the effect of cytokinins sources on foliar senescence delaying in shoots of Annona glabra L. and its implications on its development. Node segments were cultivated in test tubes containing $15 \mathrm{~mL}$ of WPM medium, supplemented with $30 \mathrm{~g} \mathrm{~L}^{-1}$ of sucrose, $500 \mathrm{mg} \mathrm{L}^{-1}$ of benomyl and $1 \mathrm{~g} \mathrm{~L}^{-1}$ of activated charcoal. It was added to this medium 6-benzilaminopurine, thidiazuron, kinetin and zeatin, all of them in the concentration of $1 \mathrm{mg} \mathrm{L}^{-1}$. After 45 days of inoculation, plants were submitted to senescence in a dark environment during 9 days, and the leaves were collected in each three days for quantification of chlorophylls "a" and " $b$ ", carotenoids, proteins and total soluble sugar. In the final steps of multiplication and rooting, it was obtained a dry matter accumulation, a foliar area index and the number of abscised leaves in plants without senescence treatments. The experimental design used was random blocks, and each senescence period was composed by a block, with four replicates per treatment. The results showed that kinetin and zeatin, followed by thidiazuron and 6-benzilaminopurine, preserved the higher chlorophylls "a" and "b" and carotenoids levels during the period of induced senescence. The 6-benzilaminopurine and kinetin promoted higher foliar area retention during the multiplication and rooting phases of Annona glabra L.
\end{abstract}

Index terms: Chlorophyll, Annonaceae, Carotenoids.

\section{INTRODUÇÃO}

Annona glabra L., espécie frutífera tropical, tem sido bastante pesquisada como porta-enxerto para anonáceas cultivadas. O interesse por este material é devido à tolerância do sistema radicular a condições de excesso de umidade no solo e à indução de nanismo à copa enxertada. Além disso, possui potencial fitofarmacológico, apresentando propriedades antibactericidas, antifúngicas, inseticidas e citotóxicas (Padmaja et al., 1995).

Como técnica opcional para multiplicação de anonáceas, tem-se empregado a micropropagação, havendo na literatura um considerável número de informações acerca dos fatores que afetam sua morfogênese in vitro (Rasai et al., 1995). Para tanto, tem-se utilizado basicamente uma fonte de citocinina, acrescida ao meio de cultivo. O BAP, isoladamente ou em combinação com outros reguladores de crescimento, tem sido empregado em

(Trabalho 155-2006). Recebido em: 05-10-2006. Aceito para publicação em 08-12-2006.

${ }^{2}$ Prof., Dept ${ }^{\circ}$ de Ciências Biológicas, Universidade Estadual de Feira de Santana, av. Universitária, 44031-460, Feira de Santana-BA, Brasil (lenaldo@uefs.br); 3 Prof., Dept ${ }^{\circ}$ de Biologia, Universidade Federal de Lavras, CP. 3037, CEP 37200-000, Lavras-MG, Brasil, renpaiva@ufla.br; tel.: (35) 3829-1359;

${ }^{4}$ Prof., Dept ${ }^{\circ}$ de Ciências Biológicas, Universidade Estadual de Feira de Santana, av. Universitária, 44031-460, Feira de Santana-BA, Brasil, raniere@ uefs.br; ${ }^{5}$ Pós-doutoranda FAPEMIG, Dept ${ }^{\circ}$ de Biologia, Universidade Federal de Lavras, CP. 3037, CEP 37200-000, Lavras-MG, Brasil, rairys@yahoo.com.br; ${ }^{6}$ Doutoranda, Dept $^{\circ}$ de Biologia, Universidade Federal de Lavras, CP. 3037, CEP 37200-000, Lavras-MG, Brasil, fernandapereirasoares@yahoo.com.br; ${ }^{7}$ Graduando, Dept ${ }^{\circ}$ de Biologia, Universidade Federal de Lavras, CP. 3037, CEP 37200-000, Lavras-MG, Brasil, lucout@yahoo.com.br; 
concentrações entre 0,2 a $2,0 \mathrm{mg} \mathrm{L}^{-1}$ na maioria dos sistemas de micropropagação, a exemplo dos trabalhos realizados com atemóia e A. cherimola Mill. (Encina et al., 1994), A. muricata L. (Lemos \& Blake, 1996a) e A. squamosa L. (Nagori \& Purohit, 2004).

Entretanto, a multiplicação in vitro e em larga escala de anonáceas ainda tem se confrontado com algumas limitações. A contaminação endógena dos explantes (Santana et al., 2003), a alta concentração de compostos fenólicos em seus tecidos e, principalmente, a abscisão foliar precoce (Lemos, 2000), ocasionada pelo acúmulo de etileno nos tecidos confinados no ambiente in vitro, prejudicando o vigor e o crescimento das brotações, são os principais exemplos. Para Lemos (2000), solucionar essa dificuldade representa o grande desafio na obtenção de um protocolo consistente para a micropropagação de anonáceas. Lemos \& Blake (1996b) estudaram a ação do etileno sobre a abscisão foliar precoce em A. squamosa L. cultivados in vitro mediante uso de compostos absorventes, inibidores da síntese e da ação do etileno. Embora os resultados obtidos tenham mostrado redução significativa da abscisão foliar, principalmente quando foram usados inibidores da ação do etileno, os efeitos produzidos não foram duráveis. Contudo, tem-se inferido que a senescência é um processo regulado pelo balanço entre etileno e citocinina nos tecidos. A concentração de citocinina diminui abruptamente em órgãos maduros, induzindo o início da senescência. Quando se utilizam citocininas em folhas isoladas de muitas espécies, essas promovem o retardo da senescência, como observado em Alstroemeria (Ferrante et al., 2002) e Brassica oleracea L. (Downs et al., 1997). Entretanto, a competência para retardar a senescência foliar varia amplamente entre os diversos tipos de citocininas (Genkov et al., 1997).

Objetivou-se, com o presente trabalho, buscar um melhor entendimento da senescência foliar precoce em anonáceas mantidas in vitro. Comparou-se, então, o efeito de diferentes fontes de citocininas no retardo desse processo, assim como seus reflexos sobre o desenvolvimento das plantas micropropagadas de A. glabra L.

\section{MATERIAL E MÉTODOS}

Os explantes, constituídos de segmentos nodais contendo uma gema e $1,5 \mathrm{~cm}$ de comprimento, foram obtidos de plantas-matrizes de Annona glabra L. mantidas em sala de crescimento sob fotoperíodo de 16 horas e temperatura ambiente. Esses foram lavados em água corrente por 6 horas e imersos, em seguida, em álcool etílico $70 \%$, por 1 minuto, solução de hipoclorito de sódio, com $1 \%$ de cloro ativo, por 15 minutos, e água destilada e autoclavada por três vezes de 1 minuto cada. Os explantes foram isolados e mantidos em solução de ácido ascórbico na concentração de $200 \mathrm{mg} \mathrm{L}^{-1}$, por 10 minutos, e inoculados em tubos de ensaio $(25 \times 150 \mathrm{~mm})$ contendo $15 \mathrm{~mL}$ do meio Wood Plant Medium (WPM), definido por Lloyd \& McCown (1980), suplementado com $30 \mathrm{~g} \mathrm{~L}^{-1}$ de sacarose, 500 $\mathrm{mg} \mathrm{L}^{-1}$ de benomyl e $1 \mathrm{~g} \mathrm{~L}^{-1}$ de carvão ativado. $\mathrm{O}$ meio foi solidificado com
$0,65 \%$ de ágar, tendo seu $\mathrm{pH}$ ajustado para 5,7 antes da autoclavagem. Os tratamentos consistiram da adição de 6benzilaminopurina (BAP), thidiazuron (TDZ), cinetina (KIN) e zeatina (ZEA), todos na concentração de $1 \mathrm{mg} \mathrm{L}^{-1} \mathrm{e}$, como controle, utilizou-se o tratamento sem adição de citocinina. Apenas ZEA foi filtrada em filtro milipore (22ì m de malha) e adicionada após autoclavagem do meio. Após a inoculação dos explantes, procedeu-se à vedação dos tubos com tampas e filmes plásticos. Os explantes foram mantidos no escuro, por um período de 7 dias, sendo, em seguida, transferidos para ambiente com fotoperíodo de 16 horas, irradiância de fótons de $50 \mu \mathrm{mol} \mathrm{m}^{-2} \mathrm{~s}^{-1} \mathrm{e}$ temperatura de $27 \pm 2^{\circ} \mathrm{C}$. Para o enraizamento, as plantas multiplicadas sob diferentes fontes de citocininas foram transferidas para meio WPM, suplementado com $30 \mathrm{~g} \mathrm{~L}^{-1}$ de sacarose, $1 \mathrm{~g} \mathrm{~L}^{-1}$ de carvão ativado e $2 \mathrm{mg} \mathrm{L}^{-1}$ de AIB (ácido indolbutírico) e $\mathrm{pH}$ do meio ajustado para 5,0, antes da autoclavagem.

Após 45 dias da inoculação inicial em meio de multiplicação, selecionaram-se 48 tubos de cada tratamento, contendo plantas com aproximadamente o mesmo tamanho e aspecto. Essas plantas foram submetidas à senescência em ambiente escuro, por um período de 9 dias, realizando-se, nesse período, 4 coletas de folhas para análises bioquímicas (uma coleta a cada três dias). Em cada período, procederam-se à quantificação de clorofila "a", clorofila "b", clorofila total $(a+b)$, carotenóides, proteínas e açúcares solúveis totais (AST).

A quantificação de clorofila "a", "b" e total $(a+b)$ foi realizada por espectrofotometria de ultravioleta, conforme método proposto por Arnon (1949), realizando-se leituras espectrofotométricas a 645 e $663 \mathrm{~nm}$. Para a quantificação dos carotenóides totais, procedeu-se à extração em hexano e posterior leitura espectrofotométrica a 450nm, segundo método AOAC (1990). Para análise do teor de AST, adotou-se o método de antrona (Dische, 1962), utilizando-se como padrão de glicose anidro. A determinação da fração protéica foi realizada por meio do doseamento do nitrogênio total pelo método Micro-Kjeldahl (AOAC, 1995), utilizando-se do fator de 6,25 para conversão dos valores de nitrogênio total para fração protéica. Os experimentos foram analisados como blocos casualizados, sendo cada período de senescência considerado um bloco, com quatro repetições por tratamento e três plantas por repetição.

Aos 55 dias após a inoculação, período correspondente ao final da fase de multiplicação, quantificaram-se, nas plantas que não foram submetidas à senescência em ambiente escuro, a matéria seca, a área foliar, o número de folhas que sofreram abscisão e o percentual da área foliar correspondente. Essas mesmas avaliações foram realizadas no final da fase de enraizamento. Para a determinação da área foliar, foi utilizado um scanner HP4C deskjet, acoplado a um PC K6II 400MHz, quantificando-se a área correspondente a cada imagem com o auxílio do software QUANT (Fernandes Filho et al., 2001). Para análise estatística, foi utilizado o programa SISVAR 4.3 (Ferreira, 1999). As médias foram comparadas pelo teste de Scott \& Knott, a $5 \%$ de probabilidade.

Rev. Bras. Frutic., Jaboticabal - SP, v. 29, n. 1, p. 025-030, Abril 2007 
TABELA 1 - Teor de clorofila "a", clorofila "b" e clorofila "a + b" em folhas de Annona glabra L. cultivadas in vitro na presença de diferentes fontes de citocininas e submetidas à senescência induzida.

\begin{tabular}{|c|c|c|c|c|}
\hline \multirow{2}{*}{$\begin{array}{l}\text { Fonte de } \\
\text { citocinina }\end{array}$} & \multicolumn{4}{|c|}{ Tempo de senescência induzida (Dias) } \\
\hline & 0 & 3 & 6 & 9 \\
\hline \multicolumn{5}{|c|}{ Clorofila "a" ( $\left.\mu \mathrm{g} \mathrm{g}^{-1} \mathrm{MS}\right)$} \\
\hline Controle & $131,13 \mathrm{c}$ & $115,02 \mathrm{~d}$ & $111,48 \mathrm{~d}$ & $91,67 \mathrm{~d}$ \\
\hline TDZ & $128,44 \mathrm{~d}$ & $118,81 \mathrm{c}$ & $114,09 \mathrm{c}$ & $104,85 \mathrm{~b}$ \\
\hline BAP & $134,13 \mathrm{~b}$ & $117,64 \mathrm{c}$ & $111,54 \mathrm{~d}$ & $95,09 \mathrm{c}$ \\
\hline KIN & 141,31 a & $133,22 \mathrm{~b}$ & $127,61 \mathrm{~b}$ & $120,95 \mathrm{a}$ \\
\hline ZEA & 142,14 a & $135,86 \mathrm{a}$ & $132,28 \mathrm{a}$ & $122,19 \mathrm{a}$ \\
\hline DMS & 2,858 & & & \\
\hline $\mathrm{CV}(\%)$ & 0,78 & & & \\
\hline \multicolumn{5}{|c|}{ Clorofila "b" $\left(\mu \mathrm{g} \mathrm{g} \mathrm{g}^{-1} \mathrm{MS}\right)$} \\
\hline Controle & $51,35 \mathrm{c}$ & $41,19 \mathrm{~b}$ & $33,28 \mathrm{~d}$ & $23,23 \mathrm{e}$ \\
\hline TDZ & $51,87 \mathrm{c}$ & $47,49 \mathrm{a}$ & $37,96 \mathrm{c}$ & $31,80 \mathrm{c}$ \\
\hline BAP & $52,95 \mathrm{c}$ & $48,45 \mathrm{a}$ & $41,12 \mathrm{~b}$ & $27,57 \mathrm{~d}$ \\
\hline KIN & $61,15 \mathrm{a}$ & $46,99 \mathrm{a}$ & $43,87 \mathrm{a}$ & $40,38 \mathrm{a}$ \\
\hline ZEA & $56,33 \mathrm{~b}$ & $46,32 \mathrm{a}$ & $41,38 \mathrm{~b}$ & $37,49 \mathrm{~b}$ \\
\hline DMS & 3,149 & & & \\
\hline $\mathrm{CV}(\%)$ & 2,53 & & & \\
\hline & \multicolumn{4}{|c|}{ Clorofila "a + b" $\left(\mu \mathrm{g} \mathrm{g}^{-1} \mathrm{MS}\right)$} \\
\hline Controle & $182,48 \mathrm{~d}$ & $156,52 \mathrm{c}$ & $144,61 \mathrm{c}$ & $114,91 \mathrm{~d}$ \\
\hline TDZ & $180,32 \mathrm{~d}$ & $166,31 \mathrm{~b}$ & $152,05 \mathrm{~b}$ & $136,66 \mathrm{~b}$ \\
\hline BAP & $187,09 \mathrm{c}$ & $166,10 \mathrm{~b}$ & $152,65 \mathrm{~b}$ & $122,67 \mathrm{c}$ \\
\hline KIN & $202,47 \mathrm{a}$ & $180,21 \mathrm{a}$ & $171,49 \mathrm{a}$ & $161,34 \mathrm{a}$ \\
\hline ZEA & $198,48 \mathrm{~b}$ & $182,18 \mathrm{a}$ & $173,92 \mathrm{a}$ & $159,66 \mathrm{a}$ \\
\hline DMS & 2,262 & & & \\
\hline $\mathrm{CV}(\%)$ & 0,85 & & & \\
\hline
\end{tabular}

*Em cada coluna, as médias seguidas pelas mesmas letras não diferem significativamente entre si, pelo teste de Scott-Knott, a 5\% de probabilidade. DMS - diferença mínima significativa.

\section{RESULTADOS E DISCUSSÃO}

Verificou-se efeito significativo das fontes de citocininas e do período de escuro sobre as variáveis analisadas. Aos 45 dias de cultivo, KIN e ZEA promoveram maior acúmulo de clorofila "a" e "b". BAP, TDZ e o tratamento sem adição de citocinina promoveram efeitos semelhantes nesse mesmo período (Tabela 1). Esse mesmo padrão manteve-se ao longo dos nove dias em ambiente escuro; entretanto, as diferenças entre os tratamentos tornaram-se mais acentuadas. Com nove dias de tratamento no escuro, as plantas cultivadas na presença de KIN e ZEA apresentaram teores de clorofila " $\mathrm{a}+\mathrm{b}$ " praticamente iguais

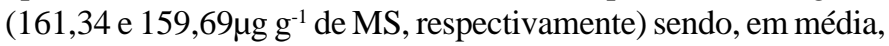
$17,44 \% ; 30,82 \%$ e $39,67 \%$ superiores em relação aos resultados obtidos nas plantas submetidas aos tratamentos com TDZ, BAP e sem adição de citocinina, respectivamente. Nesse mesmo período, a razão clorofila $\mathrm{a} / \mathrm{b}$ foi significativamente menor nas plantas submetidas aos tratamentos com adição de citocininas $(2,99 ; 3,25 ; 3,44$ e 3,29 para KIN, ZEA, BAP e TDZ,
TABELA 2 - Teor de carotenóides, proteínas e açúcares solúveis totais (AST) em folhas de Annona glabra L. cultivadas in vitro na presença de diferentes fontes de citocininas e submetidas à senescência induzida.

\begin{tabular}{|c|c|c|c|c|}
\hline \multirow{2}{*}{$\begin{array}{l}\text { Fonte de } \\
\text { citocinina }\end{array}$} & \multicolumn{4}{|c|}{ Tempo de senescência induzida (Dias) } \\
\hline & 0 & 3 & 6 & 9 \\
\hline \multicolumn{5}{|c|}{ Carotenóides $\left(\mu \mathrm{g} \mathrm{g}^{-1} \mathrm{MS}\right)$} \\
\hline Controle & $6,74 \mathrm{~d}$ & $3,94 \mathrm{c}$ & $1,80 \mathrm{~d}$ & $1,67 \mathrm{~d}$ \\
\hline TDZ & $7,05 \mathrm{c}$ & $5,57 \mathrm{~b}$ & $2,92 \mathrm{c}$ & $2,90 \mathrm{~b}$ \\
\hline BAP & $6,98 \mathrm{c}$ & $5,49 \mathrm{~b}$ & $2,91 \mathrm{c}$ & $2,46 \mathrm{c}$ \\
\hline $\mathrm{KIN}$ & $8,24 \mathrm{~b}$ & $5,69 \mathrm{~b}$ & $3,25 \mathrm{~b}$ & $3,06 \mathrm{~b}$ \\
\hline ZEA & $8,84 \mathrm{a}$ & $5,93 \mathrm{a}$ & $3,70 \mathrm{a}$ & $3,37 \mathrm{a}$ \\
\hline DMS & 0,23 & & & \\
\hline $\mathrm{CV}(\%)$ & 2,54 & & & \\
\hline \multicolumn{5}{|c|}{ Proteínas $\left(\mathrm{mg} \mathrm{g}^{-1} \mathrm{MS}\right)$} \\
\hline Controle & $8,46 \mathrm{~b}$ & $7,34 \mathrm{c}$ & $6,35 \mathrm{a}$ & $6,01 \mathrm{~b}$ \\
\hline TDZ & $8,48 \mathrm{~b}$ & $8,20 \mathrm{a}$ & $6,50 \mathrm{a}$ & $6,33 \mathrm{~b}$ \\
\hline BAP & $8,05 \mathrm{c}$ & $7,24 \mathrm{c}$ & $6,43 \mathrm{a}$ & $6,19 b$ \\
\hline KIN & $8,89 \mathrm{a}$ & $8,30 \mathrm{a}$ & $6,71 \mathrm{a}$ & $6,70 \mathrm{a}$ \\
\hline ZEA & $7,96 \mathrm{c}$ & $7,79 \mathrm{~b}$ & $6,32 \mathrm{a}$ & $6,30 \mathrm{~b}$ \\
\hline DMS & 0,40 & & & \\
\hline CV $(\%)$ & 2,93 & & & \\
\hline \multicolumn{5}{|c|}{ AST (mg g $\left.{ }^{-1} \mathrm{MS}\right)$} \\
\hline Controle & $0,74 \mathrm{c}$ & $1,98 \mathrm{a}$ & $2,85 \mathrm{a}$ & $2,94 \mathrm{a}$ \\
\hline TDZ & $0,98 \mathrm{a}$ & $1,83 \mathrm{~b}$ & $2,25 \mathrm{~b}$ & $2,40 \mathrm{~b}$ \\
\hline BAP & $0,88 \mathrm{~b}$ & $1,88 \mathrm{~b}$ & $2,25 \mathrm{~b}$ & $2,47 \mathrm{~b}$ \\
\hline KIN & $1,03 \mathrm{a}$ & $1,28 \mathrm{~d}$ & $1,59 \mathrm{c}$ & $2,05 \mathrm{c}$ \\
\hline ZEA & $0,88 \mathrm{~b}$ & $1,40 \mathrm{c}$ & $1,66 \mathrm{c}$ & $2,11 \mathrm{c}$ \\
\hline DMS & 0,09 & & & \\
\hline CV (\%) & 2,81 & & & \\
\hline
\end{tabular}

respectivamente). Nas plantas multiplicadas na ausência de citocinina, esse valor foi de 3,94.

O teor de carotenóides totais foi afetado positivamente pela presença de citocinina no meio de cultura durante todo o período de indução da senescência foliar (Tabela 2). No início do tratamento em ambiente escuro, ZEA, seguida de KIN promoveram os maiores valores de carotenóides totais, enquanto, nos tratamentos com TDZ, BAP e sem adição de citocinina, os teores de carotenóides foram semelhantes. Com nove dias de escuro, as plantas cultivadas na presença de ZEA, KIN, TDZ e BAP apresentaram teores de carotenóides superiores em $101,79 \% ; 83,23 \% ; 73,65 \%$ e $47,30 \%$, em relação às plantas cultivadas em meio sem adição de citocinina, respectivamente. $\mathrm{O}$ teor de proteínas sofreu uma redução gradativa durante a senescência induzida, embora tenha sido pouco afetada pela presença de citocininas, principalmente aos seis e nove dias de escuro. KIN, TDZ e ZEA demonstraram pequeno efeito na inibição da degradação protéica, principalmente após três dias de escuro (Tabela 2). 
TABELA 3 - Matéria seca, área foliar, número de folhas senescentes e percentual de área foliar senescente no final das fases de multiplicação e enraizamento de Annona glabra L. cultivadas in vitro na presença de diferentes fontes de citocininas.

\begin{tabular}{ccccc}
\hline $\begin{array}{c}\text { Fonte de } \\
\text { citocinina }\end{array}$ & $\begin{array}{c}\text { Matéria } \\
\text { seca } \\
(\mathrm{g})\end{array}$ & $\begin{array}{c}\text { Área foliar } \\
\left(\mathrm{cm}^{2}\right)\end{array}$ & $\begin{array}{c}\mathrm{N}^{\mathrm{o}} \text { de folhas } \\
\text { senescentes }\end{array}$ & $\begin{array}{c}\text { Área foliar } \\
\text { senescente } \\
(\%)\end{array}$ \\
\hline \multicolumn{5}{c}{ Multiplicação } \\
Controle & $0,016 \mathrm{~b}$ & $4,16 \mathrm{~b}$ & $2,40 \mathrm{a}$ & $11,24 \mathrm{a}$ \\
TDZ & $0,020 \mathrm{~b}$ & $2,62 \mathrm{~b}$ & $1,80 \mathrm{a}$ & $10,26 \mathrm{a}$ \\
BAP & $0,022 \mathrm{~b}$ & $6,34 \mathrm{a}$ & $1,00 \mathrm{~b}$ & $5,70 \mathrm{~b}$ \\
KIN & $0,044 \mathrm{a}$ & $4,68 \mathrm{~b}$ & $0,60 \mathrm{~b}$ & $3,28 \mathrm{~b}$ \\
ZEA & $0,044 \mathrm{a}$ & $3,43 \mathrm{~b}$ & $2,60 \mathrm{a}$ & $13,02 \mathrm{a}$ \\
& & & & \\
\hline DMS & 0,012 & 1,56 & 0,68 \\
\hline CV $(\%)$ & 22,82 & 33,82 & 40,12 \\
\hline \multicolumn{7}{c}{ Enraizamento } \\
Controle & $0,082 \mathrm{~b}$ & $4,55 \mathrm{~b}$ & $3,40 \mathrm{a}$ & $19,16 \mathrm{a}$ \\
TDZ & $0,111 \mathrm{~b}$ & $5,81 \mathrm{~b}$ & $2,40 \mathrm{a}$ & $12,30 \mathrm{~b}$ \\
BAP & $0,165 \mathrm{a}$ & $8,87 \mathrm{a}$ & $0,80 \mathrm{~b}$ & $5,460 \mathrm{c}$ \\
KIN & $0,170 \mathrm{a}$ & $11,25 \mathrm{a}$ & $0,60 \mathrm{~b}$ & $4,240 \mathrm{c}$ \\
ZEA & $0,082 \mathrm{~b}$ & $6,85 \mathrm{~b}$ & $2,00 \mathrm{a}$ & $10,98 \mathrm{~b}$ \\
\hline DMS & 0,05 & 2,54 & 1,12 & 5,89 \\
\hline CV $(\%)$ & 21,93 & 22,62 & 39,21 & 36,16 \\
\hline
\end{tabular}

* Em cada fase da micropropagação e na mesma coluna, as médias seguidas pelas mesmas letras não diferem significativamente entre si, pelo teste de Scott-Knott, a 5\% de probabilidade. DMS - Diferença mínima significativa.

Os teores de AST sofreram um aumento gradativo durante o período escuro. Com o início do tratamento em ambiente escuro e durante todo o período de senescência induzida, as plantas cultivadas em meio sem adição de citocinina apresentaram maiores teores de AST, sendo estatisticamente superiores a partir do sexto dia de tratamento no escuro. ZEA e KIN foram as fontes de citocininas que promoveram menores acúmulos de AST durante o período escuro. As plantas mantidas na presença de BAP e TDZ apresentaram valores intermediários de AST e semelhantes estatisticamente no sexto e nono dias de senescência induzida.

Durante a fase de multiplicação das brotações de $A$. glabra L., apenas o BAP estimulou maior desenvolvimento de área foliar entre as fontes de citocininas testadas. Nessa mesma fase, BAP e KIN promoveram a maior retenção da área foliar, em virtude do menor número de folhas senescentes (Tabela 3), enquanto KIN e ZEA estimularam o maior acúmulo de matéria seca. Já durante a fase de enraizamento, as plantas que foram multiplicadas na presença de BAP e KIN, apresentaram maior retenção de área foliar, seguida das plantas multiplicadas em meio com ZEA e TDZ. Já nas plantas multiplicadas em meio com ausência de citocinina exógena, verificou-se menor retenção foliar. Os maiores valores de matéria seca, no final da fase de enraizamento, foram observados nas plantas cultivadas em meio com BAP e KIN.
Neste trabalho, verificou-se uma ação efetiva das fontes de citocinina testadas sobre o retardo na degradação de clorofilas durante a senescência induzida em brotações de A. glabra L. (Tabela 1). A efetividade da ZEA no retardo da degradação de clorofila confirma a maior atividade dessa fonte natural de citocinina no cultivo in vitro de anonáceas, conforme resultados obtidos por Encina et al. (1994). Para Sing et al. (1992), a maior atividade dessa fonte de citocinina decorre de sua maior capacidade de conjugação com açúcares, tornando-as mais resistentes à clivagem enzimática. Entre as fontes sintéticas, a KIN mostrou-se como a mais eficiente no retardo da degradação de clorofila. TDZ e BAP demonstraram pouca efetividade no controle da degradação de clorofilas, apesar da elevada atividade do BAP na indução de brotações de anonáceas (Lemos \& Blake, 1996a), e do TDZ na inibição da senescência foliar em Alstroemeria (Ferrante et al., 2002). Entretanto, Carimi et al. (2004) demonstraram que o BAP, em concentrações elevadas, pode promover a morte celular programada em cultura de células, acelerando a senescência.

A adição de citocinina ao meio de cultura, mesmo antes do início do tratamento no escuro, induziu uma redução na razão clorofila a/b. Para Engel \& Poggiani (1991), a proporção entre clorofilas " $a$ " e "b" tende a diminuir com a redução da intensidade luminosa, condição freqüente no ambiente in vitro, com maior proporção relativa de clorofila "b". Para esses mesmos autores, o aumento no teor de clorofila "b" está associado a uma degradação mais lenta desse pigmento, quando comparado com a clorofila "a". A menor razão clorofila a/b pode representar aumento na eficiência fotossintética das plantas submetidas à baixa intensidade de fluxo de fótons, pois maior proporção relativa de clorofila "b" possibilita a captação de outros comprimentos de onda. De modo semelhante, a preservação de carotenóides nas folhas, devido à adição de citocininas (Tabela 2), pode possibilitar maior captação de energia pelos fotossistemas, atuando na fotoproteção das membranas fotossintéticas, como sugerido por Chernyad'ev (2000).

A menor degradação de clorofilas e carotenóides durante a senescência induzida, nos tratamentos com citocininas, resultou em menor acumulação de AST nos tecidos foliares, já que esses compostos resultam, em parte, da própria degradação desses pigmentos (Quirino et al., 2000). A presença de citocinina no meio de cultura praticamente não afetou o teor de proteínas nas folhas, principalmente aos seis e nove dias em ambiente escuro, diferentemente dos resultados obtidos por Kulaeva et al. (2002), avaliando a senescência induzida em Hordeum vulgare L. na presença de BAP, sugerindo participação ativa desses compostos na biossíntese de proteínas nos cloroplastos.

A adição de citocinina ao meio de cultura teve reflexos positivos sobre a retenção da área foliar nas brotações durante as fases de multiplicação e enraizamento, em virtude da menor taxa de abscisão foliar (Tabela 3), principalmente quando se utilizaram BAP e KIN. Mesmo tendo sido menos efetivo na preservação de clorofilas e carotenóides durante a senescência induzida, o BAP foi mais eficiente na prevenção da abscisão foliar precoce. Isso redundou em maior preservação da área foliar, confirmando sua grande efetividade no cultivo in vitro de 
anonáceas, conforme resultados obtidos por Lemos \& Blake (1996a) e Nagori \& Purohit (2004). BAP e KIN induziram também maior acúmulo de matéria seca durante as fases de multiplicação e enraizamento das plantas. Foram, em média, 104,2\% superiores em relação aos valores obtidos com adição de ZEA e sem a adição de citocinina e $50,9 \%$ superiores em relação ao obtido no tratamento com TDZ, demonstrando que o efeito do BAP e da KIN estende-se além da fase em que foram adicionados ao meio de cultura.

A adição de ZEA, apesar de ter promovido maior prevenção na degradação de clorofilas e carotenóides, durante o período de indução da senescência, não assegurou menor taxa de abscisão foliar e, conseqüentemente, maior retenção de área foliar durante as fases de multiplicação e de enraizamento das brotações, refletindo-se em menor acúmulo de matéria seca nestas fases. A pequena área foliar nessas plantas resultou também da reduzida expansão das folhas, evidenciando efeito tóxico dessa fonte de citocinina na concentração utilizada. Encina et al. (1994), estudando a morfogênese em explantes de A. cherimola Mill., já haviam reportado a formação de brotos anormais com a utilização de ZEA.

\section{CONCLUSÕES}

1. A adição de citocininas ao meio de cultura permite uma redução da senescência foliar durante o cultivo in vitro de $A$. glabra L.

2. As fontes de citocininas BAP e KIN permitem maior retenção de área foliar e maior acúmulo de matéria seca durante o cultivo in vitro dessa espécie, possibilitando maior desenvolvimento das brotações.

\section{AGRADECIMENTOS}

À Fundação de Amparo à Pesquisa do Estado de Minas Gerais (FAPEMIG), pelo apoio financeiro à condução deste trabalho.

\section{REFERENCIAS}

AOAC - ASSOCIATION OF OFFICIAL ANALYTICAL CHEMISTS. Official methods of analysis of the Association of Official Analytical Chemists. $15^{\text {th }}$ ed. Washington, DC, 1990. $1298 \mathrm{p}$.

AOAC - ASSOCIATION OF OFFICIAL ANALYTICAL CHEMISTS. Official methods of analysis of the Association of Official Analytical Chemists. $17^{\text {th }}$ ed. Arlington, 1995. 1141p.

ARNON, D. I. Copper enzymes in isolated chloroplasts: polyphenoloxydase in Beta vulgaris. Plant Physiology, Maryland, v. 24, n. 1, p. 1-15, Jan. 1949.

CARIMI, F.; TERZI, M.; DE MICHELE, R.; ZOTTINI, M.; SCHIAVO, F. L. High levels of the cytokinin BAP induce PDC by accelerating senescence. Plant Science, Clare, v. 166, n. 4, p. 963-969, Apr. 2004.
CHERNYAD'EV, I. I. Ontogenetic Changes in the Photosynthetic Apparatus and Effects of Cytokinins (Review). Applied Biochemistry and Microbiology, Moscou, v. 36, n. 6, p. 527 539, 2000.

DISCHE, Z. General color reactions. In: WHISTLER, R. L.; WOLFRAM, M. L. (Ed.). Carbohydrate chemistry. New York: Academic Press, 1962. p. 477-512.

DOWNS, C. G.; SOMERFIELD, S. D.; DAVERY, M. C. Cytokinin treatment delays senescence but not sucrose loss in harvested broccoli. Postharvest Biology and Technology, Amsterdam, v. 11, n. 2, p. 93-100, June 1997.

ENCINA, C.L.; BARCELÓ-MUNHOZ,A.;HERRERO-CASTAÑO, A.; PLIEGO-ALFARO, F. In vitro morphogenesis of juvenile Annona cherimola Mill. Bud explants. Journal of Horticultural Science, Ashford, v. 69, n. 6, p. 1053-1059, Nov. 1994.

ENGEL, V.L.; POGGIANI, F. Estudo da concentração de clorofila nas folhas e seu espectro de absorção de luz em função do sombreamento em mudas de quatro espécies florestais nativas. Revista Brasileira de Fisiologia Vegetal, Londrina, v.3, n.1, p.39-45, jun. 1991.

FERRANTE, A.; HUNTER, D. A.; HACKETT, W. P.; REID, M. S. Thidiazuron - a potent inhibitor of leaf senescence in Alstroemeria. Postharvest Biology and Technology, Amsterdam, v. 25, n. 3, p. 333-338, July 2002.

FERREIRA, D. F. SISVAR 4.3: sistema de análises estatísticas. Lavras: UFLA, 1999.

GENKOV, T.; TSONEVA, P.; IVANOVA, I. Effect of cytokinins on photosynthetic pigments and chlorophyllase acticity in in vitro cultures of axillary buds of Dianthus caryophyllus L. Journal Plant Growth Regulatory, New York, v. 16, n. 3, p. 169-172, 1997.

KULAEVA, O. N.; BURKHANOVA, E. A.; KARAVAIKO, N. N.; SELIVANKINA, S. Y.; PORFIVORA, S. A.; MASLOVA, G. G.; ZEMLYACHENKO, Y. V.; BORNER, T. Chloroplasts affect the leaf response to cytokinin. Journal of Plant Physiology, Leipzig, v. 159, n. 12, p. 1309-1316, Dec. 2002.

LEMOS, E. E. P. Organogênese e micropropagação em anonáceas. In: WORKSHOP SOBREAVANÇOS NAPROPAGAÇÃODE PLANTAS LENHOSAS, 3., 2000, Lavras. Anais... Lavras: UFLA, 2000. p. 4-21.

LEMOS, E. E. P.; BLAKE, J. Control of leaf abscission in nodal cultures of Annona muricata L. Journal of Horticultural Science, Ashford, v. 71, n. 5, p. 721-728, Sept. 1996a.

LEMOS, E. E. P.; BLAKE, J. Micropropagation of juvenile and mature Annona muricata L. Journal of Horticultural Science, Ashford, v. 71, n. 3, p. 395-403, May 1996b.

LLOYD, G.; McCOWN, B. Use of microculture for production and improvement of Rhododendron spp. HortScience, Alexandria, v. 15, p. 416, Aug. 1980. Abstract 321.

NAGORI, R.; PUROHIT, S. D. In vitro plantled regeneration in Annona squamosa L. through direct shoot bud differentiation on hypocotyl segments. Scientia Horticulturae, Amsterdam, v. 99, n. 1, p. 89-98, Jan. 2004. 
PADMAJA, V.; THANKAMANY, V.; HARA, N.; FUJIMOTO, Y.; HISHAM, A. Biological activities of Annona glabra. Journal of Ethnopharmacology, Clare, v. 48, n. 1, p. 21-24, Aug. 1995. QUIRINO, B. F.; NOH, Y. S.;HIMELBLAU, E.; AMASINO, R. M. Molecular aspects of leaf senescence. Trends Plant Science, London, v. 5, n. 7, p. 278-282, July 2000.

RASAI, S.; GEORGE, A. P.; KANTHARAJAH, A. S. Tissue culture of Annona spp. (Cherimoya, atemoya, sugar apple and soursop): a review. Scientia Horticulturae, Amsterdam, v. 62, n. 1/2, p. 1-14, Apr. 1995.

SANTANA, J. R. F. de; PAIVA, R.; ALOUFA, M. A. I.; LEMOS, E. E. P. Efficiency of amplicillin and benomyl at controlling contamination of Annonaceae leaf segments cultured in vitro. Fruits, Paris, v. 58, n. 4, p. 357-361, 2003.

SING, S.; LETHAM, D. S.; PALINI, L. M. S. Cytokinin biochemistry in relation to leaf senescence. Physiologia Plantarum, Copenhagen, v. 86, n. 3, p. 388-397, Nov. 1992. 